\title{
CARDIOVASCULAR MANIFESTATIONS IN PATIENTS OF HYPOTHYROIDISM- RESULTS OF A SINGLE CENTRE STUDY
}

\author{
Rohit Vasant Deshpande1, Swati Harish Sharma², Swapnil Sahebrao Walke3, Mayur Ramakrishnarao Hedau4, Bharat Sing Rathod5, \\ Amol Raghunath Bhore, ${ }^{6}$ Hitesh Lotan Mahale

\begin{abstract}
${ }^{1}$ Associate Professor, Department of General Medicine, Grant Government GMC and Sir J. J. Group of Hospitals, Mumbai. ${ }^{2}$ Senior Resident, Department of General Medicine, Grant Government GMC and Sir J. J. Group of Hospitals, Mumbai. ${ }^{3}$ Ex-Resident, Department of General Medicine, Grant Government GMC and Sir J. J. Group of Hospitals, Mumbai. ${ }^{4}$ Lecturer, Department of General Medicine, Grant Government GMC and Sir J. J. Group of Hospitals, Mumbai.

${ }_{5}^{5}$ Associate Professor, Department of General Medicine, Grant Government GMC and Sir J. J. Group of Hospitals, Mumbai.

${ }^{6}$ Lecturer, Department of General Medicine, Grant Government GMC and Sir J. J. Group of Hospitals, Mumbai.
\end{abstract} \\ ${ }^{7}$ Ex-Resident, Department of General Medicine, Grant Government GMC and Sir J. J. Group of Hospitals, Mumbai.
}

\section{ABSTRACT}

\section{BACKGROUND}

Objective- To examine cardiovascular manifestations in patients with hypothyroidism.

\section{MATERIALS AND METHODS}

In this observational study, adult hypothyroid patients were screened for cardiovascular disease. Symptoms of hypothyroidism, cardiovascular system related symptoms, T3, T4 and Thyroid Stimulating Hormone (TSH) were compared between male and female patients. Association between thyroid stimulating hormone and heart disease was also evaluated.

\section{RESULTS}

Hundred patients (male $32 \%$ and female $68 \%$ ) with mean age of $39.2+9.28$ years were enrolled. More number of females showed weight gain over a period of two years as compared to males $(p=0.0217)$. Dry skin was more common in females as compared to males $(p=0.0336)$. More females reported breathlessness and chest pain as compared to males (breathlessness $p=0.0187$; chest pain $p=0.0008)$. Pulse rate of female patients was significantly lower than male patients $(p=0.0081)$. More number of females had raised jugular venous pressure as compared to males ( $41 \%$ vs $19 \%, p=0.0475)$. Diastolic blood pressure was higher in females than in males $(\mathrm{p}=0.023)$. There was no difference in the mean T3 $(52.43 \pm 14.35 \mathrm{pg} / \mathrm{mL}$ vs $46.53 \pm 14.19 \mathrm{pg} / \mathrm{mL} ; \mathrm{p}=0.1776)$, T4 level ( $4.48 \pm 0.97$ vs $4.06 \pm 0.97 ; p=0.1630)$ or TSH level (31.19 \pm 11.9 vs $42.21 \pm 26.98 ; p=0.1260)$ between males and females. Number of females with cardiomegaly was higher compared to males [26 (38\%) vs $2(6 \%) ; p<0.0001]$. Significant association was observed between higher TSH and presence of breathlessness, chest discomfort and palpitations ( $<<0.05)$. Significantly, more patients with higher TSH showed significantly more heart rate, raised jugular venous pressure and diastolic blood pressure (p < 0.05). Higher TSH was associated with pericardial effusion in more proportion of patients $(p=0.007)$.

\section{CONCLUSION}

Cardiac dysfunction is common in patients with hypothyroidism. Screening and treatment of cardiovascular disease in hypothyroidism may help to reduce morbidity and mortality in hypothyroidism.

\section{KEYWORDS}

Cardiovascular Manifestations, Hypothyroidism, Thyroid Stimulating Hormone.

HOW TO CITE THIS ARTICLE: Deshpande RV, Sharma SH, Walke SS, et al. Cardiovascular manifestations in patients of hypothyroidism- results of a single centre study. J. Evolution Med. Dent. Sci. 2017;6(45):3514-3518, DOI: $10.14260 /$ Jemds/2017/758

\section{BACKGROUND \\ Hypothyroidism is a common endocrinological problem in clinical practice. The reported incidences of clinical hypothyroidism range from 0.5 to $1.9 \%$ in women and less than $1 \%$ in men. Subclinical hypothyroidism is more common than clinical hypothyroidism, both in females and males. ${ }^{1}$ The prevalence of subclinical hypothyroidism is about $4-10.5 \%{ }^{2}$ Both clinical and subclinical hypothyroidism are shown to be associated with cardiovascular manifestations. As heart is}

Financial or Other, Competing Interest: None.

Submission 22-04-2017, Peer Review 24-05-2017,

Acceptance 30-05-2017, Published 05-06-2017.

Corresponding Author:

Dr. Rohit Vasant Deshpande,

Kant Apartment, A- Wing-1104,

Near Mount Mary Church, Bandra- West-400050,

Maharashtra, India.

E-mail: coolrohit258@gmail.com

DOI: $10.14260 /$ jemds $/ 2017 / 758$

\section{(c) $(1) \ominus$}

the major target organ for action of thyroid hormones, changes can occur in cardiac structure and function in patients with hypothyroidism. ${ }^{3-5}$ Diastolic hypertension and sinus bradycardia are the common cardiac manifestations of hypothyroidism. The other reported cardiovascular problems reported include heart block, cardiomyopathy, pericarditis and pericardial effusion. ${ }^{3}$

The effect of subclinical hypothyroidism on the cardiovascular system is an important topic of research. Link between subclinical hypothyroidism and several cardiovascular risk factors such as blood pressure, atherosclerosis and metabolic syndrome has been suggested. ${ }^{6}$ In Indian patients, subclinical hypothyroidism has been shown to be associated with dyslipidaemia more commonly as compared to control group. ${ }^{2}$ Timely identification of cardiac abnormalities and its management in hypothyroid patients may help to reduce morbidity and mortality. There are very limited studies in Indian population suggesting relationship between hypothyroidism and cardiac disorders. 


\section{Objective}

The objectives of the study were to find out prevalence and compare the cardiovascular manifestations of hypothyroidism in males and females and to study the relationship between Thyroid Stimulating Hormone (TSH) levels and cardiovascular manifestations.

\section{MATERIALS AND METHODS}

In this observational study, adult ( $>18$ years of age) hypothyroid patients from a tertiary care hospital in Mumbai were included by convenience sampling. Patients with history of cardiac disease, diabetes mellitus or those taking medications that alter the thyroid function (e.g. beta blockers, lithium, oral contraceptive pills, alcohol, amiodarone, etc.) were excluded. After detailed history, physical examination, systemic examination and laboratory investigations (complete blood count, serum T3, T4 and TSH, serum electrolytes, renal function test, liver function test, serum lipid profile, electrocardiography, echocardiography), enrolled patients were screened for cardiovascular disease based on symptomatology, physical examination, chest x-ray, Electrocardiography (ECG) and echocardiography. Symptoms of hypothyroidism, cardiovascular system related symptoms,
T3, T4 and TSH were compared between male and female patients. Association between thyroid stimulating hormone and heart disease was also evaluated. The study was initiated after obtaining the permission from the Institutional Ethics Committee.

\section{Statistical Analysis}

The quantitative data is presented as mean and standard deviation, whereas categorical data is expressed in percentage. The t-test was used for analysing quantitative data. Non-parametric data was analysed by using MannWhitney test and categorical data was analysed by chi-square test. $\mathrm{P}$ value less than 0.05 was considered statistically significant. Statistical analysis was carried out using SPSS software version 21.

\section{RESULTS}

A total of 100 hypothyroid patients (male 32\% and female $68 \%$ ) with mean age of $39.2+9.28$ years were enrolled in the study. The mean age of males and females was $39.43 \pm 10.53$ years and $39.12 \pm 8.81$ years respectively $(p=0.9109)$. Number of females were more compared to male patients ( $p$ $<0.015$ ).

\begin{tabular}{|c|c|c|c|c|c|c|c|c|c|c|}
\hline & \multicolumn{2}{|c|}{ Weight Gain } & \multicolumn{2}{|c|}{$\begin{array}{c}\text { Generalised Weakness } \\
\text { and Fatigability }\end{array}$} & \multicolumn{2}{|c|}{$\begin{array}{c}\text { Cold } \\
\text { Intolerance }\end{array}$} & \multicolumn{2}{|c|}{ Dry Skin } & \multicolumn{2}{|c|}{ Hair loss } \\
\hline & $\begin{array}{l}\text { Male } \\
\text { N (\%) }\end{array}$ & $\begin{array}{c}\text { Female } \\
\text { N (\%) }\end{array}$ & $\begin{array}{c}\text { Male } \\
\text { N (\%) }\end{array}$ & $\begin{array}{c}\text { Female } \\
\text { N (\%) }\end{array}$ & \begin{tabular}{c|} 
Male \\
N (\%)
\end{tabular} & $\begin{array}{c}\text { Female } \\
\text { N (\%) }\end{array}$ & $\begin{array}{l}\text { Male } \\
\text { N (\%) }\end{array}$ & $\begin{array}{c}\text { Female } \\
N(\%)\end{array}$ & $\begin{array}{l}\text { Male } \\
\text { N (\%) }\end{array}$ & $\begin{array}{c}\text { Female } \\
\text { N (\%) }\end{array}$ \\
\hline$<6$ months & -- & -- & -- & -- & -- & -- & $2(6 \%)$ & 0 & $2(6 \%)$ & 0 \\
\hline 6 months & $2(3.12 \%)$ & $6(8.82 \%)$ & $6(19 \%)$ & $18(26 \%)$ & 0 & $16(24 \%)$ & $2(6 \%)$ & $16(24 \%)$ & $2(6 \%)$ & $10(15 \%)$ \\
\hline 1 year & 0 & $12(17.64 \%)$ & $2(6 \%)$ & $12(18 \%)$ & 0 & $4(6 \%)$ & $4(13 \%)$ & $12(18 \%)$ & 0 & $2(3 \%)$ \\
\hline 2 years & 0 & $4(5.88 \%)$ & 0 & $4(6 \%)$ & 0 & 0 & 0 & $2(3 \%)$ & 0 & 0 \\
\hline Absent & $\begin{array}{c}30 \\
(93.75 \%) \\
\end{array}$ & $\begin{array}{c}46 \\
(67.64 \%) \\
\end{array}$ & $\begin{array}{c}24 \\
(75 \%) \\
\end{array}$ & $\begin{array}{c}34 \\
(50 \%) \\
\end{array}$ & $\begin{array}{c}32 \\
(100 \%) \\
\end{array}$ & $\begin{array}{c}48 \\
(71 \%) \\
\end{array}$ & $\begin{array}{c}24 \\
(75 \%) \\
\end{array}$ & $\begin{array}{c}38 \\
(56 \%) \\
\end{array}$ & $\begin{array}{c}28 \\
(88 \%) \\
\end{array}$ & $\begin{array}{c}56 \\
(82 \%) \\
\end{array}$ \\
\hline \begin{tabular}{|c|} 
P value using \\
Chi Square Test
\end{tabular} & \multicolumn{2}{|c|}{0.0217} & \multicolumn{2}{|c|}{0.0790} & \multicolumn{2}{|c|}{---} & \multicolumn{2}{|c|}{0.0336} & \multicolumn{2}{|c|}{--} \\
\hline & & & ible & Imp & $H y$ & yyroidism & & & & \\
\hline
\end{tabular}

Significantly more number of females showed weight gain over a period of two years as compared to males (Table 1; P= 0.0217). There was no difference in number of males and females having generalised weakness and fatigue over a period of two years (Table 1; $\mathrm{P}=0.0790)$. Cold tolerance was reported in only females; $16(24 \%)$ since 6 months and $4(6 \%)$ since 1 year (Table 1). Dry skin was significantly more common in females as compared to males $(\mathrm{p}=0.0336)$. Hair loss was reported by $2(6 \%)$, males since less than 6 months and 6 months each. A total of $10(15 \%)$ females reported hair loss since 6 months and 2 (3\%) since one year. A total of 8 (12\%) females reported menorrhagia since 6 months. Menorrhagia was absent in 60 (88\%) females.

\begin{tabular}{|c|c|c|c|c|c|c|c|c|}
\hline & \multicolumn{2}{|c|}{ Depression } & \multicolumn{2}{|c|}{ Constipation } & \multicolumn{2}{|c|}{ Muscle and Joint Pain } & \multicolumn{2}{|c|}{ Slowness of Speech } \\
\hline & $\begin{array}{c}\text { Male } \\
\text { N (\%) }\end{array}$ & $\begin{array}{c}\text { Female } \\
\text { N (\%) }\end{array}$ & $\begin{array}{c}\text { Male } \\
\text { N (\%) }\end{array}$ & $\begin{array}{c}\text { Female } \\
\text { N (\%) }\end{array}$ & $\begin{array}{c}\text { Male } \\
\text { N (\%) }\end{array}$ & $\begin{array}{c}\text { Female } \\
\text { N (\%) }\end{array}$ & $\begin{array}{c}\text { Male } \\
\text { N (\%) }\end{array}$ & $\begin{array}{c}\text { Female } \\
\text { N (\%) }\end{array}$ \\
\hline$<6$ months & $2(6 \%)$ & $2(3 \%)$ & 0 & $4(6 \%)$ & -- & -- & 0 & $2(3 \%)$ \\
\hline 6 months & $2(6 \%)$ & 0 & 0 & 0 & 0 & $6(9 \%)$ & $2(6 \%)$ & $4(6 \%)$ \\
\hline 1 year & 0 & 0 & 0 & 0 & 0 & 0 & 0 & $4(6 \%)$ \\
\hline 2 years & $4(13 \%)$ & $2(3 \%)$ & 0 & 0 & 0 & 0 & 0 & 0 \\
\hline Absent & $24(75 \%)$ & $64(94 \%)$ & $32(100 \%)$ & $64(94 \%)$ & $32(100 \%)$ & $62(91 \%)$ & $30(94 \%)$ & $58(85 \%)$ \\
\hline P value & \multicolumn{2}{|c|}{ - ---- } & \multicolumn{2}{|c|}{--- } & \multicolumn{2}{|c|}{---- } & \multicolumn{2}{|c|}{---} \\
\hline \multicolumn{9}{|c|}{ Table 2. Other Symptoms } \\
\hline
\end{tabular}

Depression was presented by $2(6 \%)$ males and 2 (3\%) females since less than 6 months and in $2(6 \%)$ males since 6 months. In $4(13 \%)$ male patients and $2(3 \%)$ females, depression was present since 2 years. Constipation since less than 6 months was reported by $4(6 \%)$ females. Muscle and joint pain was present in $6(9 \%)$ females since 6 months. Slowness of speech was reported by $2(6 \%)$ male patients since 6 months, whereas $2(3 \%), 4(6 \%)$ and $4(6 \%)$ females reported it since less than 6 months, 6 months and 1 year respectively (Table 2). 


\begin{tabular}{|c|c|c|c|c|c|c|}
\hline & \multicolumn{2}{|c|}{ Breathlessness } & \multicolumn{2}{|c|}{ Chest Pain } & \multicolumn{2}{|c|}{ Palpitation } \\
\hline & $\begin{array}{c}\text { Male } \\
\text { N (\%) } \\
\end{array}$ & $\begin{array}{c}\text { Female } \\
\text { N (\%) }\end{array}$ & $\begin{array}{c}\text { Male } \\
\text { N (\%) } \\
\end{array}$ & $\begin{array}{c}\text { Female } \\
\text { N (\%) }\end{array}$ & $\begin{array}{c}\text { Male } \\
\text { N (\%) }\end{array}$ & $\begin{array}{c}\text { Female } \\
\text { N (\%) }\end{array}$ \\
\hline$<6$ months & $4(13 \%)$ & $6(9 \%)$ & $2(6 \%)$ & $14(21 \%)$ & -- & -- \\
\hline 6 months & $2(6 \%)$ & $14(21 \%)$ & 0 & $8(12 \%)$ & 0 & $6(9 \%)$ \\
\hline 1 year & 0 & $10(15 \%)$ & 0 & $10(15 \%)$ & 0 & $6(9 \%)$ \\
\hline Absent & $26(81 \%)$ & $38(56 \%)$ & $30(94 \%)$ & $36(53 \%)$ & $32(100 \%)$ & $56(825)$ \\
\hline P value using Chi Square Test & \multicolumn{2}{|c|}{0.0187} & \multicolumn{2}{|c|}{0.0008} & \multicolumn{2}{|c|}{----- } \\
\hline
\end{tabular}

Significantly, more number of females reported breathlessness and chest pain over a period of 2 years as compared to males (breathlessness $\mathrm{p}=0.0187$; chest pain $\mathrm{p}=0.0008)$. Palpitation was reported by $6(9 \%)$ females, each since 6 months and one year (Table 3).

\begin{tabular}{|c|c|c|c|}
\hline $\begin{array}{c}\text { Parameter } \\
\text { Mean } \pm \text { SD }\end{array}$ & Males (n=16) & Females (n=34) & P-value (Comparison between Males and Females) \\
\hline Pulse rate (beats per min) & $80.37 \pm 6.24$ & $74.35 \pm 6.24$ & 0.0081 \\
\hline Raised JVP n (\%) & $6(19 \%)$ & $28(41 \%)$ & 0.0475 \\
\hline Systolic BP & $132.5 \pm 9.84$ & $130.18 \pm 8.63$ & 0.4001 \\
\hline Diastolic BP & $89.13 \pm 5.80$ & $93.06 \pm 2.88$ & 0.0023 \\
\hline \multicolumn{2}{|r}{ Table 4. Comparison of Physical Examination between Males and Females } \\
\hline
\end{tabular}

The mean pulse rate of males and females was $80.37 \pm 6.24$ beats $/ \mathrm{min}$ and $74.35 \pm 6.24$ beats/min respectively. Pulse rate of female patients was significantly lower than male patients $(p=0.0081)$. Significantly, more proportion of females had raised jugular venous pressure as compared to males ( $41 \%$ vs $19 \%, p=0.0475$; Table 4 ). There was no significant difference in systolic blood pressure between males and females ( $\mathrm{p}=0.4001)$, whereas diastolic blood pressure was significantly higher in females than in males (Table 4; $\mathrm{p}=0.023)$. Muffled heart sound was observed in $2(6 \%)$ males and $30(44 \%)$ females. Significantly, more number of females had abnormal heart sound as compared to males $(\mathrm{p}<0.0001)$.

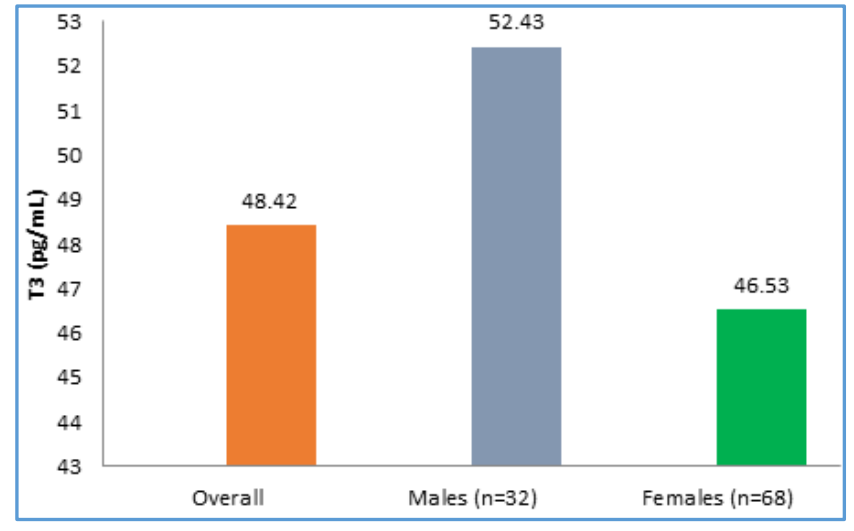

Figure 1. Level of T3 in Males and Females

Overall, mean T3 was $48.42 \pm 14.37 \mathrm{pg} / \mathrm{mL}$. There was no difference in the mean T3 of males and females (52.43 \pm $14.35 \mathrm{pg} / \mathrm{mL}$ vs $46.53 \pm 14.19 \mathrm{pg} / \mathrm{mL}$; $\mathrm{p}=0.1776$; Figure 1 ).

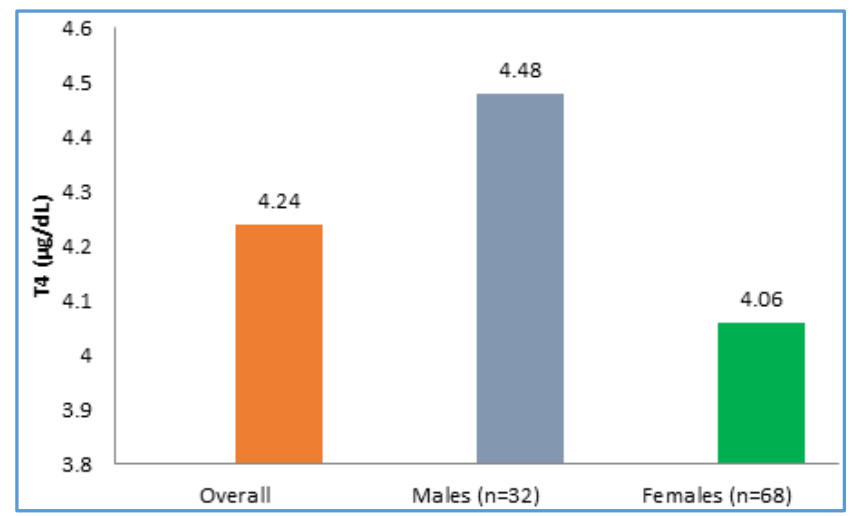

Figure 2. Level of T4 in Males and Females
Overall, mean T4 was $4.24 \pm 0.94 \mathrm{mcg} / \mathrm{dL}$. There was no difference in the mean T4 level of males and females (4.48 \pm 0.97 vs $4.06 \pm 0.97 ; p=0.1630$; Figure 2 ).

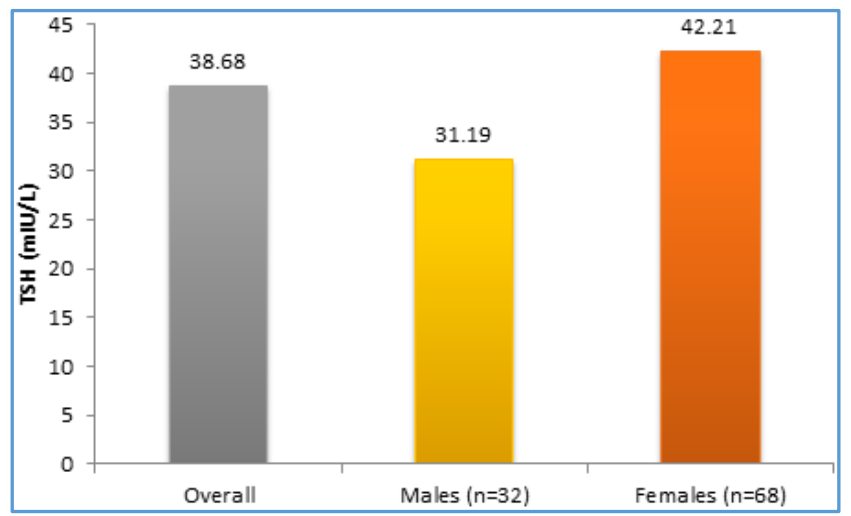

Figure 3. Level of TSH in Males and Females

Overall, mean TSH level was $38.68 \pm 23.68$. There was no significant difference in mean TSH level in males and females (31.19 \pm 11.9 vs $42.21 \pm 26.98 ; p=0.1260$; Figure 3 ).

Significantly, more number of females showed cardiomegaly on chest $\mathrm{x}$-ray compared to males [26 (38\%) vs 2 (6\%); $<<0.0001]$.

Overall, ECG was normal in $52(52 \%)$ patients, whereas some abnormality was observed in $48(48 \%)$ patients. There was no abnormality in ECG in $75 \%$ (24/32) males and $29.41 \%(20 / 68)$ females. Low voltage in ECG was observed in $18.75 \%(6 / 32)$ males and $35.29 \%(24 / 68)$ females. A total of $6.25 \%(2 / 32)$ male and $23.53 \%(16 / 68)$ females had left ventricular hypertrophy, whereas $8.82 \%$ and $2.94 \%$ females showed atrial fibrillation and first degree heart block respectively. 
The echocardiogram was normal in 46 (46\%) patients. No abnormality in Echo was found in $81.25 \%$ (26/32) males and $47.06 \%(32 / 68)$ females. Diastolic dysfunction was observed in $18.75 \%(6 / 32)$ males and $58.82 \%(46 / 68)$ females $(\mathrm{p}=$ $0.0139)$. Pericardial effusion was seen in $18.75 \%(6 / 32)$ males and $44.12 \%(30 / 68)$ females, $(p=0.1171)$.

\section{Association between TSH Levels and Cardiovascular Manifestations}

Association between TSH and Cardiovascular Symptoms

In 10 - 39 years of age group there were 16 (16\%) patients with breathlessness, 14 (14\%) patients complained of chest discomfort and $4(4 \%)$ had palpitation. In $40-79$ years of age group there were $14(14 \%)$ patients with breathlessness, 10 (10\%) patients complained of chest discomfort and 2 (2\%) patients had palpitations. In above 80 years of age group, 6 $(6 \%)$ patients had breathlessness and $6(6 \%)$ each had chest discomfort and palpitations. Significant association was observed between higher TSH and presence of breathlessness, chest discomfort and palpitations $(\mathrm{p}<0.05)$.

\section{Association between TSH and Cardiovascular Signs}

In 10 - 39 years' age group the mean heart rate was $78.54+$ 10.96 beats/min, 16 (16\%) patients had raised jugular venous pressure, whereas $48(48 \%)$ patients had a diastolic $\mathrm{BP}$ of more than $90 \mathrm{mmHg}$. In the $40-79$ years' age group the mean heart rate was $75.71+8.40$ beats/min, $12(12 \%)$ patients had raised jugular venous pressure and 24 (24\%) patients had a diastolic BP more than $90 \mathrm{mmHg}$. In the above 80 years' age group, the mean heart rate was $134.66+4.50$ beats/min, $6(6 \%)$ patients had raised jugular venous pressure, while $10(10 \%)$ patients had a diastolic BP more than $90 \mathrm{mmHg}$. Significantly, more patients with higher TSH showed significantly more heart rate, raised jugular venous pressure and diastolic blood pressure $(\mathrm{p}<0.05)$.

\section{Association between TSH and ECG Findings}

Low voltage complexes $(p=0.0476)$ and left ventricular hypertrophy $(p=0.0492)$ were present in significantly greater proportion of patients in 10 - 39 years' age group, while atrial fibrillation was present in significantly greater proportion of patients in patients above 80 years of age ( $p<$ $0.0001)$.

\section{Association between TSH and Echocardiography Findings \\ There was no difference in proportion of patients with and without diastolic dysfunction with different TSH levels ( $p=$ 0.1775 ). Higher TSH was associated with pericardial effusion in more proportion of patients $(\mathrm{p}=0.007)$.}

\section{DISCUSSION}

Hypothyroidism is known to be associated with several cardiac disorders. However, there are limited data from India suggesting the correlation between these two disorders and difference in cardiovascular disease pattern between male and female patients with hypothyroidism. In this study, we evaluated the prevalence and compared pattern of cardiovascular manifestations in patients diagnosed with hypothyroidism. The mean age of 39.22 years in this study suggests common occurrence of hypothyroidism in Indian adult patients. Number of female patients was significantly more compared to males in our study. Our observation of mean age and gender difference is similar to a study from India. ${ }^{7}$

Clinical features of hypothyroidism include fatigue, dry skin, cold intolerance, hoarseness of voice, bradycardia, constipation and weight gain. ${ }^{1}$ We observed weight gain and generalised weakness and fatigability in more number of females. In our study, cold intolerance was reported in only females. Overall, the number of patients reporting cold intolerance and women with menorrhagia were less compared to another study. However, the number of patients with dry skin was similar. ${ }^{8}$ Significantly, more number of females reported breathlessness over a period of two years as compared to males $(\mathrm{p}=0.0187)$. Total number of patients with breathlessness was less compared to a study by Sureshbabu KP and Colleagues. ${ }^{8}$

We also found significantly more number of females complaining chest discomfort over a period of 2 years as compared to males. Similarly, significantly more number of females showed raised jugular venous pressure as compared to males $(p=0.0475)$. In a study by Dhawale $S$ et al $(2015),{ }^{9}$ reported $19 \%$ patients exhibiting cardiovascular symptoms. There was not a significant difference in the cardiovascular symptoms between males and females. The mean pulse rate of our study population was comparable to another study from India. ${ }^{7}$ In our study, there was no significant difference in systolic blood pressure between males and females. Diastolic hypertension is a known cardiac abnormality in patients with hypothyroidism. ${ }^{3}$ Diastolic blood pressure was significantly higher in females than in males in our study. Other studies have not shown significant difference in systolic and diastolic blood pressure between males and females. ${ }^{9,10}$

Significantly, more number of females had abnormal heart sound as compared to males ( $p<0.0001)$ in our study. We did not find other studies comparing heart sounds between male and female patients of hypothyroidism. We also did not find difference in male and female population in T3, T4 or TSH levels.

The number of patients with normal chest x-ray findings in our study are in accordance to the reported observations by others. ${ }^{11}$ In our study, significantly more number of females showed cardiomegaly on chest $\mathrm{x}$-ray as compared to males $(\mathrm{p}<0.0001)$.

A study from South India has shown pericardial effusion, diastolic dysfunction, bradycardia and low voltage complexes in ECG. ${ }^{2}$ Low voltage complexes, left ventricular hypertrophy, atrial fibrillation and first degree heart block were reported in ECGs of hypothyroid patients in our study. More number of females had diastolic dysfunction in our study.

Overt hypothyroidism is known to be associated with cardiovascular disease. Results of the Rotterdam Study have showed that even subclinical hypothyroidism is a risk factor for atherosclerosis and myocardial infarction in elderly women. ${ }^{13}$

Increased involvement of cardiovascular system has been reported with raising levels of TSH.12

Results of the Cardiovascular Health study have shown high risk of heart failure in older patients with elevated TSH level. ${ }^{14}$ In our study also, higher TSH level was significantly associated with abnormal cardiovascular problems as compared to lower TSH levels ( $p<0.0001)$. 
There are no studies found on the parameters such as depression, hair loss, constipation, slowness of speech, palpitations, raised jugular venous pressure, cardiovascular manifestation, chest x-ray findings and correlation between the different levels of TSH and cardiovascular manifestation.

There are some limitations in our study. Considering convenience sampling, single centre study and limited patient population, results of our study should be carefully extrapolated.

\section{CONCLUSION}

Hypothyroidism is associated with several cardiac abnormalities. The cardiovascular disease in hypothyroidism is treatable and potentially preventable. Mass education, screening and treatment of cardiovascular disease in hypothyroidism may help to reduce cardiovascular morbidity and mortality in hypothyroidism.

\section{REFERENCES}

[1] Kostoglou-Athanassiou I, Ntalles K. Hypothyroidismnew aspects of an old disease. Hippokratia 2010;14(2):82-7.

[2] Asranna A, Taneja RS, Kulshreshta B. Dyslipidemia in subclinical hypothyroidism and the effect of thyroxine on lipid profile. Indian J Endocrinol Metab 2012;16(Suppl 2):S347-9.

[3] Grais IM, Sowers JR. Thyroid and the heart. Am J Med 2014;127(8):691-8.

[4] Kahaly GJ, Dillmann WH. Thyroid hormone action in the heart. Endocr Rev 2005;26(5):704-28.

[5] Vílchez FG, Castillo L, Pi J, et al. Cardiac manifestations of primary hypothyroidism. Determinants factors and treatment response. Rev Esp Cardiol 1998; 51(11): 893-900.
[6] Suh S, Kim DK. Subclinical hypothyroidism and cardiovascular disease. Endocrinol Metab 2015;30(3):246-51.

[7] Jagdish, Singh H, Siwach SB, et al. An echocardiographic study on the effect of levothyroxine therapy on cardiac function and structure in hypothyroidism. Journal of Indian Academy of Clinical Medicine 2009;10(1 \& 2):27-31.

[8] Sureshbabu KP, Gireesh, Oswal A. Cardiac manifestations in hypothyroidism-a cross sectional study. RJPBCS 2014;5(3):966-75.

[9] Dhawale S, Gaharwar R, Jayant SS. Study of cardiovascular manifestations in patients of hypothyroidism with special reference to TMT (Tread Mill Test). International Journal of Multidisciplinary Research and Development 2015;2:515-23.

[10] Mayer 0, Šimon J, Filipovský J, et al. Hypothyroidism in coronary heart disease and its relation to selected risk factors. Vasc Health Risk Manag 2006;2(4):499506.

[11] Alzaidy MS. Cardiovascular manifestations of hypothyroidism. Medical Journal of Babylon 2011;8:592-601.

[12] Ramesh K, Nayak BP. A study of cardiovascular involvement in hypothyroidism. IAIM 2016;3(5):7480.

[13] Hak AE, Pols HA, Visser T], et al. Subclinical hypothyroidism is an independent risk factor for atherosclerosis and myocardial infarction in elderly women: the rotterdam study. Ann Intern Med 2000;132(4):270-8.

[14] Rodondi N, Bauer DC, Cappola AR, et al. Subclinical thyroid dysfunction, cardiac function, and the risk of heart failure. The cardiovascular health study. J Am Coll Cardiol 2008;52(14):1152-9. 